\title{
Evaluating the Role of Scientific Awards
}

\author{
Science prizes can motivate scientists to take risks and think outside the \\ box, but data show that not all groups share in this motivating experience.
}

\author{
By Ching Jin and Brian Uzzi
}

$\square$ eople get excited about prizes, and scientists are no different, as the past week of Nobel prizes has demonstrated. But beyond the hoopla, scientific awards can serve a purpose in setting science's future direction. As social scientists investigating human achievement, our studies on the impact of prizes on prizewinners, and on science as a whole, have shown that awards are doing a good job at motivating certain scientists to pursue high-risk, high-reward research and in drawing attention and resources to

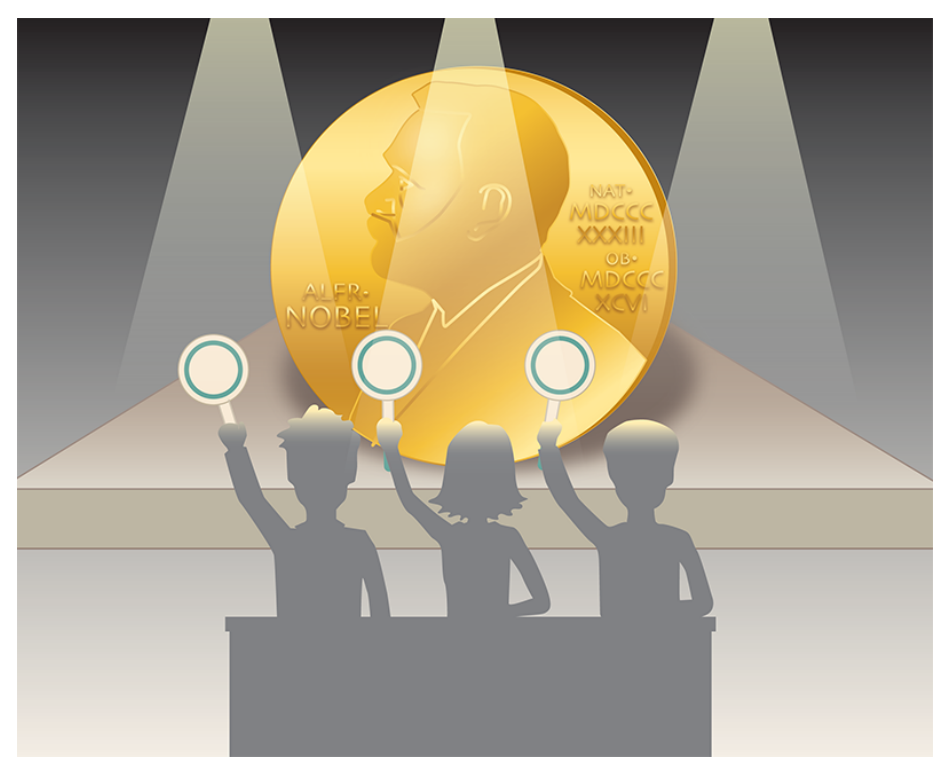

Scientific prizes, like the Nobel prize, can serve a benefit to science, but recent analyses show that the award process could be improved, especially in recognizing underrepresented groups. Credit: APS/Carin Cain cutting-edge science. But these benefits are not uniform. Women and other groups are underrepresented as prizewinners, and while prizes are more numerous than ever, the awardees are increasingly concentrated in a relatively small group of scientists. Compared to its sibling fields, physics has the farthest to go toward a fair distribution of prizes, but there are signs that the situation is improving.

Harriet Zuckerman, the famed sociologist of science, outlined the intended goals of scientific prizes. First, prizes are motivators. Scientists toil in their labs or at their computers for various reasons: financial compensation, earning tenure, or the privilege to engage in a labor of love. But beyond these motivating factors, prizes offer a distinctive personal incentive to conduct high-risk, high-return science. Many prizewinners have reported that, while their objective was to do good science-for instance, by creating a life-saving drug or an environmentally friendly technology-it was the chance to win a prize that spurred them to shed blood, sweat, and tears in search of a discovery. Second, prizes strengthen community bonds and establish role models that can be cherished by aspiring scientists. Awards are generally given at annual meetings followed by celebrations that unite researchers in that scientific field. Third, prizes recognize research topics, thereby raising the collective perception of a topic's scientific and societal value. The Nobel Committee awarded half of this year's Nobel Prize in Physics to climate researchers (see Nobel Prize: Complexity, from Atoms to Atmospheres), which elevates the topic and stresses that it rests on a solid physics background.

Do prizes meet these goals? The advent of huge datasets on 
prizes, prizewinners, and scientists' careers allows, for the first time, the examination of the impact of prizes on science [1]. For example, we can track how a field benefits from the limelight of an award. Our research shows that the year after a topic is associated with a prize, the topic takes off, growing at a remarkable rate. A prizewinning topic can be expected to grow roughly $40 \%$ faster in number of participants, impact, and the in-migration of new entrants and star scientists than expected from its prior ten-year historic growth pattern [2]. Such a boost is much bigger than the growth that would be expected from the typical increase in funding to a topic by the National Institutes of Health or the National Science Foundation [3].

We can also look at the impact that prizes have on community interactions. Prizewinners appear to be good role models, as their students are more likely to win prizes than equally gifted students of equally successful scientists who haven't won prizes. This trend seems to be more than just a "halo effect" in which students of prizewinners are held in higher regard because of their mentor's award. In fact, the increased likelihood of winning a prize applies to students who worked under a prizewinning mentor ten years before the prize was awarded [4], implying that the mentor is good at passing on the skills for doing extraordinary research.

Another important aspect is the growth of prizes. Up until 1980, there were fewer prizes than there were scientific fields, but now prizes outnumber fields by a ratio of 2:1, with the annual growth in new prizes doubling every 20 years [5]. At the same time, the proliferation of prizes has led to a clustering of prizes in the hands of fewer scientists, who are multiple prizewinners. So, while the prize pie has expanded overall, a smaller proportion of scientists are reaping the benefits.

This problem of the concentration of prizes within certain groups is especially acute when we look at the number of prizes going to women. The underrepresentation of women prizewinners in physics, chemistry, and biology (Fig. 2) runs counter to the goals of prizes, as women scientists may have less incentive to do extraordinary work or may feel less sense of belonging to the community. Compared to its sibling disciplines, physics has the most prizewinners, as well as the lowest percentage of female published scholars. This deficit may be due to the fact that prizes are generally given to senior researchers, and men have been in the field, on average, longer

\begin{tabular}{|l|lccccc|}
\hline & First prize & $\begin{array}{l}\text { Prizes } \\
\text { per } \\
\text { year }\end{array}$ & $\begin{array}{l}\text { Total } \\
\text { no. of } \\
\text { winners }\end{array}$ & $\begin{array}{l}\text { Female } \\
\text { winners } \\
\text { pre-2000 }\end{array}$ & $\begin{array}{l}\text { Female } \\
\text { winners } \\
\text { post-2000 }\end{array}$ & $\begin{array}{l}\text { Female } \\
\text { published } \\
\text { scholars }\end{array}$ \\
\hline Physics & $\begin{array}{l}\text { Rumford Medal } \\
\text { (1800) }\end{array}$ & 123 & 2,977 & $3.1 \%$ & $8.8 \%$ & $21 \%$ \\
\hline $\begin{array}{l}\text { Chemistry } \\
\text { Faraday } \\
\text { Lectureship (1869) }\end{array}$ & 52 & 1,109 & $5.7 \%$ & $10.3 \%$ & $31 \%$ \\
$\begin{array}{l}\text { Biology \& } \\
\text { Medicine }\end{array}$ & $\begin{array}{l}\text { Linnean Medal } \\
(1888)\end{array}$ & 154 & 2,905 & $6.5 \%$ & $18.5 \%$ & $40 \%$ \\
\hline
\end{tabular}

A comparison of prizes in physics, chemistry, and biology. The field of physics has been offering awards for over two hundred years and currently has the highest number of winners, but the smallest percentage of women winners (both prior to and after the year 2000) and the smallest percentage of published scholars who are women [9].

than women. What's more, prizes generally go to individuals, whereas most women entered the field more recently, when most work is done in teams [6, 7]. However, these historical trends don't seem to fully explain the gender imbalance in prizes, as evidence suggests that the scientific award process displays signs of unconscious bias that favors male researchers from Europe and America [8].

Analyses like the ones above are affecting how prize associations and committees nominate and select winners. The Nobel Committee is attempting to diversify its members and to provide written instruction to nominators on how to think about worthy scientists in ways that overcome unconscious biases. There is even talk of assigning prizes retroactively to correct errors and of creating prizes for teams. Scientists too are aiding efforts to ensure that prizes are fairly given. In our work, and the work of other scholars, the tracking and study of prizes is helping to raise awareness and correct imbalances in recognition across groups, and it is furnishing the data needed to ensure that prizes are a win for all.

Ching Jin: Northwestern University, Evanston, IL, USA

Brian Uzzi: Northwestern University, Evanston, IL, USA

\section{REFERENCES}

1. S. Fortunato et al., "Science of science," Science 359 (2018).

2. C. Jin et al., "Scientific prizes and the extraordinary growth of scientific topics," Nat. Commun. 12, 5619 (2021). 
3. K. Myers, "The elasticity of science," Am. Econ. J. Appl. Econ. 12,103 (2020).

4. Y. Ma et al., "Mentorship and protégé success in STEM fields," Proc. Natl. Acad. Sci. U.S.A. 117, 14077 (2020).

5. Y. Ma and B. Uzzi, "Scientific prize network predicts who pushes the boundaries of science," Proc. Natl. Acad. Sci. U.S.A. 115, 12608 (2018).

6. S. Wuchty et al., "The increasing dominance of teams in production of knowledge," Science 316, 1036 (2007).

7. K. Börner et al., "A multi-level systems perspective for the science of team science," Sci. Transl. Med. 2 (2010).

8. A. E. Lincoln et al., "The Matilda Effect in science: Awards and prizes in the US, 1990s and 2000s," Soc. Stud. Sci. 42, 307 (2012).

9. Y. Ma et al., "Women who win prizes get less money and prestige," Nature 565, 287 (2019). 